\title{
Simple Blocking Oscillator for Waste Battery's Voltage Enhancement
}

\author{
Dewanto Harjunowibowo, Wiwit Widiawati, Anif Jamaluddin, and Furqon Idris
}

\begin{abstract}
A system based on Blocking Oscillator (BO) has been built and potentially produces high gain pulses voltage. This paper aims to discuss characteristic, work principle, and its potency of simple blocking oscillator to optimize batteries usage. The measurement of its peak to peak voltage (Vpp) and root means square voltage (Vrms) were conducted using digital oscilloscope and digital voltmeter. The experiment proves that the system produces high gain pulse electricity and driven LED without broke it out. The system could power a white LED 3.0-4.0 V using an input voltage of $0.98 \mathrm{VDC}$ from waste battery. Using blocking oscillator, a battery may be used longer and more efficient until the battery energy almost ramps out to $0.5 \mathrm{~V}$.
\end{abstract}

Index Terms-Blocking oscillator, characteristic, gain, led.

\section{INTRODUCTION}

In order to increase battery life, some experiments has been done, such as to design circuit building blocks with lower supply voltage and consuming sub-microwatt power. Reference [1] has built a circuit design which generates a DC voltage independent of the supply voltage and of temperature variations. Moreover, a circuit using a pair of BJTs and a MOSFET has been built also and worked normally using $1.3 \mathrm{~V}$ to $3.6 \mathrm{~V}$ [2]. Our target is to increase the waste battery life using simple blocking oscillator.

Oscillator is a combination of active and passive electronic devices to produces sinusoidal wave or other periodic wave [3]. Based on the wave shape production, oscillators are classified into sinusoidal oscillators, and harmonic oscillator or relaxation oscillator. According to the devices, oscillators could be classified into negative-resistance oscillator and feedback oscillator [3]. Feedback oscillator has feedback regenerative gain (positive).

A blocking oscillator is a feedback oscillator type which produces relaxation oscillation [4]. Blocking oscillator has pulse-repetitive rate driven by RC (resistance and capacitance parallelized). For a monostable triggered transistor, the pulse width of blocking oscillator (base timing) may lie in the range of nanoseconds to microseconds. A resistor $\mathrm{R}$ is connected in series with the base of the transistor and it controls the timing, that is, the pulse duration (see Fig. 1).

In the beginning, the transistor is OFF. Since the cut in base-emitter voltage $\left(V_{B E}\right)$ is approximately $0.58-0.7 \mathrm{~V}$ positive for silicon transistor [5], then $\mathrm{V}_{\mathrm{BB}}$ may be reduced to

Manuscript received July 4, 2015; revised December 23, 2015.

Dewanto Harjunowibowo, Wiwit Widiawati, and Anif Jamaluddin are with ESMART Research Group, Sebelas Maret University, Indonesia (e-mail: dewanto_h@fkip.uns.ac.id).

Furqon Idris is with Energy Management Engineer at National Electricity Company of Indonesia - PT PLN (Persero) (e-mail: puye_e02@yahoo.com). zero. Since $V_{B B}<<V_{C C}$ and does not affect the operation of circuit therefore it can be neglected.

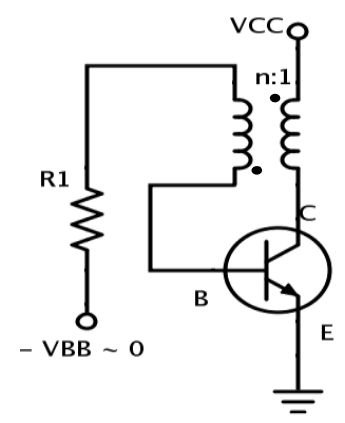

Fig. 1. A triggered transistor blocking oscillator with base timing.

Suppose a triggering signal is momentarily applied to the collector to lower its voltage. By transformer action, the base will rise in potential. After VBE exceeds the cut in voltage, the transistor saturates and starts to draw current. The increase in collector current lowers the collector voltage, which in turn raises the base voltage. Hence, more collector current flows, resulting in a further drop in collector potential. If the loop gain exceeds unity, regeneration takes place and the transistor is quickly driven into saturation. At the moment, the emitter and collector are connected so the current from collector flows to the emitter.

Afterwards, when the $V_{B E}$ decreases below the saturation voltage of transistor (cut off) hence the transistor gets OFF and the LED will shine. Since the voltage inductance of primary coils could not flows from collector to emitter which is disconnected so that the current flows to the LED which has lowest resistance, in very short time.

In this paper, blocking oscillator's characteristic using and without LED as the load are going to be discussed. White led used has voltage forward bias $V_{B f B}$ around 3.0-4.0 $\mathrm{V}$ and $I_{B f B}=$ 20mA [6]. Light-emitting-diodes (LEDs) have been widely studied and used as light sources due to their high energy efficiency in producing monochromatic light [7], [8].

Many commercial instruments and analytical systems used the compact and low-cost LEDs [9]-[11], e.g. LED-based microscopy [12]. Multi LEDs light sources have also been used for many applications [13], [14], since multiple LEDs can deliver plenty of output power while keeping the cost low.

\section{EXPERIMENTAL}

A handmade Blocking oscillator system was made using BC547 n-p- $n$ transistor, a variable resistor $5 \mathrm{~K}$, a toroid from died CFL lamp twisted 11 times by two pair Belden RJ 45 cable with ratio $1: 1$, a voltage divider $0.5-5.0 \mathrm{~V}$ from waste battery $8 \mathrm{~V}$, a white LED, and a waste battery $1.5 \mathrm{~V}$ AA which 
still has $0.98 \mathrm{~V}$. The devices were built as depicted in Fig. 2.

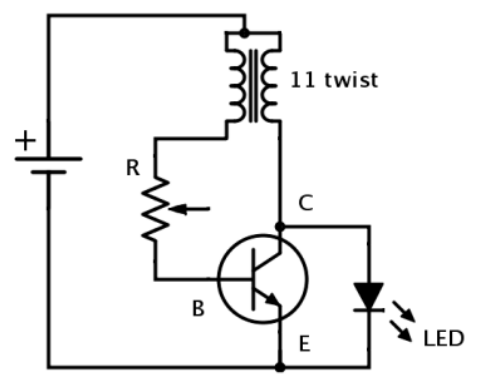

Fig. 2. Simple blocking oscillator circuit for experiment.

Using digital oscilloscope and voltmeter, voltage system on some specific parts measured and tabulated on Table I. Whereas $V$ output $\left(V_{o}\right)$ was measured with and without LED using $V$ input $\left(V_{B i B}\right)$ from $0.0-2.0 \mathrm{~V}$ and the summary reveals on Table I and Fig. 3 also Fig. 4. Afterwards, to get information of the gain potency of a power source, the $V_{o}$ was also measured using $V_{i}$ varied from 0.5-5.0 VDC without any load and the result is shown in Fig. 5.

\section{RESULTS AND DISCUSSION}

To figure out the work principle of blocking oscillator system, the peak to peak voltage $\left(V_{p p}\right)$, current $(I)$, and system frequency $(f)$ were measured. The measurements were conducted using $0.98 \mathrm{~V}$ of a waste battery when the intensity of LED was set in brightest and dullest condition. The result is shows in Table I.

It can be seen from Table I that Blocking oscillator system could gain $V_{i}$ to 5 times when adjusted to the brightest LED using potentiometer. Whereas on dullest LED, the $V_{\mathrm{BoB}}$ still has voltage gain but lower than the LED's voltage requirement.

TABLE I: RESULT OF MEASUREMENT ON $R_{\mathrm{MIN}}$ AND $R_{\mathrm{MAX}}$

\begin{tabular}{|l|l|c|c|c|c|}
\hline \multirow{3}{*}{ No } & \multirow{2}{*}{$\begin{array}{c}\text { Voltage } \\
\text { Measurement }(V)\end{array}$} & \multicolumn{2}{|c|}{$\begin{array}{c}R_{\mathrm{MIN}}=2.2(\Omega) \\
(\text { brightest })\end{array}$} & \multicolumn{2}{|c|}{$\begin{array}{c}R_{\mathrm{MAX}}=978(\Omega) \\
(\text { dullest })\end{array}$} \\
\cline { 3 - 7 } & $\begin{array}{c}\text { Voltage } \\
(\mathrm{V})\end{array}$ & $\begin{array}{c}\text { Freq. } \\
(\mathrm{kHz})\end{array}$ & $\begin{array}{c}\text { Voltage } \\
(\mathrm{V})\end{array}$ & $\begin{array}{c}\text { Freq. } \\
(\mathrm{kHz})\end{array}$ \\
\hline 1 & Without LED & 5.20 & 37.22 & 3.71 & 308.70 \\
\hline 2 & LED & 4.40 & 35.96 & 2.80 & 313.90 \\
\hline 3 & Secondary twist & 4.29 & 34.74 & 2.71 & 305.90 \\
\hline 4 & Primary twist & 4.27 & 36.22 & 2.72 & 303.10 \\
\hline 5 & Variable resistor & 0.21 & 33.39 & 2.39 & 373.20 \\
\hline 6 & Base-collector $\left(V_{\mathrm{BC}}\right)$ & 8.47 & 35.21 & 2.10 & 236.90 \\
\hline 7 & Base-emitter $\left(V_{\mathrm{BE}}\right)$ & 4.15 & 35.93 & 0.42 & 313.60 \\
\hline
\end{tabular}

The frequency of brightest and dullest condition is approximately $35 \mathrm{kHz}$ and $300 \mathrm{kHz}$, respectively. The frequency of brightest condition is much lower than the dullest. This difference caused by the resistance $R$ which controlled ON-OFF transistor timing and made pulse time longer whilst in brightest condition [15].

When the frequency of switching transistor is too fast, the pulses current which flows to inductor could not be responded by the toroid. Therefore, the current pulses is behave like a continue signal as own by normally battery. Consequently, the magnetic field response in the inductor decreases. It means there is no voltage gain produced by the inductor.

Besides the regeneration which terminates the pulse starts when the transistor comes out of saturation, the pulse width $t_{p}$ is determined as [15]:

$$
t_{p}=\frac{n L}{R}\left(h_{F E}-n\right) \approx \frac{n L h_{F E}}{R} \approx \frac{1}{f}
$$

Equation (1) depicts that raising resistance $R$ raises f raises as well. Whereas, $L$ is self inductance, $n$ is the number of twists, $h_{F E}$ is the transistor gain and $f$ is frequency.

Basically, the circuit on Fig. 2 works by rapidly switching transistor. Initially, current begins to flow through secondary winding, and base-emitter junction, which causes the transistor to begin conducting collector current through the primary winding.

Since the two windings are connected in opposing directions, this induces a voltage in the secondary winding which is positive (due to the winding polarity, see dot convention on Fig. 1) which turns the transistor ON with higher bias.

This self-stroking/positive-feedback process almost instantly turns the transistor $\mathrm{ON}$ as hard as possible (putting it in the saturation region), making the collector-emitter path look like essentially a closed switch (since $V_{C E}$ will be only about 0.1 volts, assuming that the base current is high enough). With the primary winding effectively goes across the battery, the current increases at a rate proportional to the supply voltage divided by the inductance. Transistor switch-OFF takes place by different mechanisms depending upon the supply voltage.

The predominant mode of operation relies on the non-linearity of the inductor. As the current ramps up it reaches a point, dependent upon the material and geometry of the core, where the ferrite saturates (the core may be made of material other than ferrite). The resulting magnetic field stops increasing and the current in the secondary winding are lost, depriving the transistor of base drive and the transistor starts to turn off. The magnetic field starts to collapse. Driving current in the coil into the LED (raising the voltage until conduction occurs) and the reducing magnetic field induces a reverse current in the secondary, and then turning the transistor hard OFF.

The pulse transformer is made to have an $180^{\circ}$ phase shift between primary and secondary [16]. This transformer is important because phase reversal is needed for a common emitter stage. And the gain is provided by the common emitter stage.

At lower supply voltages a different mode of operation takes place. The gain of a transistor is not linear with $V_{C E}$. At low supply voltages (typically $0.7 \mathrm{~V}$ and below) the transistor requires a larger base current to maintain saturation as the collector current increases. Hence, when it reaches a critical collector current, the available base drive becomes insufficient and the transistor starts to pinch off and the previously described positive feedback action occurs turning it hard OFF.

To summarize, once the current in the coils stops increasing for any reason, the transistor goes into the cut off region (and opens the collector-emitter "switch"). The magnetic field collapses, much inducing voltage is necessary to make the load conduct, or for the secondary-winding current to find some other path. When the field is back to zero, the whole sequence repeats; with the battery ramping-up the 
primary-winding current until the transistor switches on.

To know the characteristic gain with and without load (LED) from Blocking oscillator system, the experiment used vary of $V_{i}$ was done and the graphs result are given in Fig. 3 and Fig. 4.

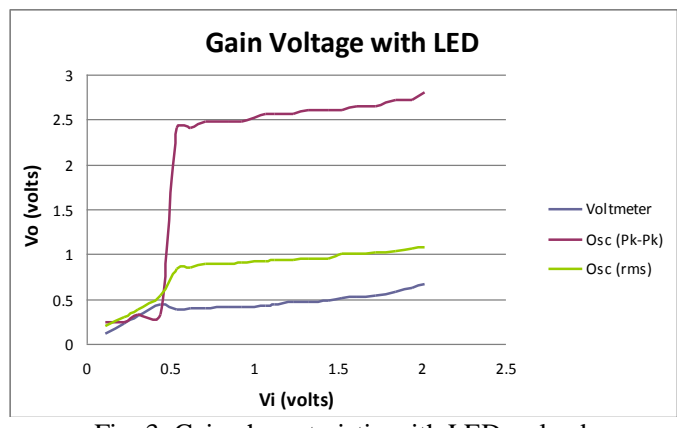

Fig. 3. Gain characteristic with LED as load.

Fig. 3 reveals the same characteristic for $V_{i}=0-2.0 \mathrm{~V}$. These voltages were varied per 0.1 volts because the system still works normally if the $V_{i}$ is approximately no more than 2 volts. When $V_{i}$ is more than 2 volts, the LED begins to light even the base circuit was disconnected. It means that the current pushes to pass the LED which has lower resistance than the transistor which was on cut off condition (open loop).

Root mean square voltage measurements were done to see whether voltmeter digital might be used to measure the pulse gain or not. $V_{r m s}$ represents the input voltage used from the battery. For this case, voltmeter can't be used to measure the gain produced by blocking oscillator system.

When the system was not used a LED as the load, it produced higher gain almost twice compared with Fig. 3 . The pulses gain slight increased when the input voltage increased as well. It means that the gain of blocking oscillator is depending with the maximum voltage needed by load. A LED has voltage forward bias approximately $2.7-3.5 \mathrm{~V}$ [6].

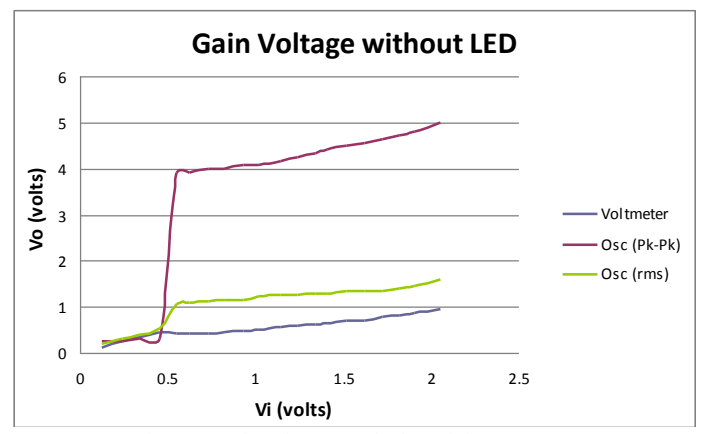

Fig. 4. Gain characteristic without LED.

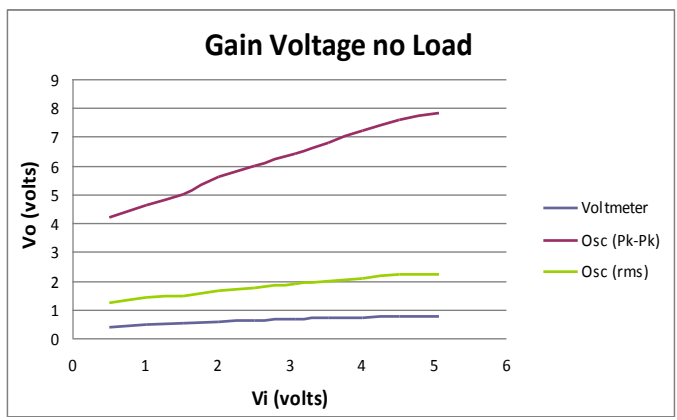

Fig. 5. Gain voltage for $0.5<V_{i}<5$ volts without load.

To get more gain information produced by $\mathrm{BO}$ whether it still could produce more gain using more input voltage, the experiment is conducted using $V_{i}=0.5-5.0 \mathrm{~V}$ from $8 \mathrm{~V}$ battery. The $V_{o}$ is measured without LED using voltmeter and oscilloscope (Fig. 5). As the result, it can bee seen from Fig. 5 that every measurements have the same result. The $V_{o}$ gain happens for every $V_{i}$, which means blocking oscillator system is potential to make gain more than $V_{i}$. The gain only limited by load which is used by the system.

The interesting characteristic of blocking oscillator is that $V_{o}$ has a DC type pulse (Fig. 6). The pulse, as switching transistor effect caused the LED and transistor safe and operates normally although the voltage that passed these devices is bigger than normally needed. The excess voltage was converted to heat which is trivial because the current is so small so that the dissipated power is also very small as well.

The pulse shows as in channel $1(\mathrm{CH} 1)$ of Fig. 6 is the gain of voltage come from battery (output voltage). The other $(\mathrm{CH} 2)$ is the input voltage used from battery. Symbol a shows the delay time of switch transistor when it was in cut off condition (OFF) and $b$ is the switch transistor on saturates condition $(\mathrm{ON})$. The declivity of the peak of curve happens since the basis voltage $\left(V_{B E}\right)$ decreases quickly to less than $0.4 \mathrm{~V}$.

On the brightest condition the output current $I_{o}=0.12 \mathrm{~mA}$ while on the dullest condition $I_{o}=0.1 \mathrm{~mA}$ are lower than input current $I_{i}=0.225 \mathrm{~mA}$. Ohms Law stated that when $R$ increases then $V$ and $I$ decrease as is indicated in equation 2 [15].

$$
V=I R
$$

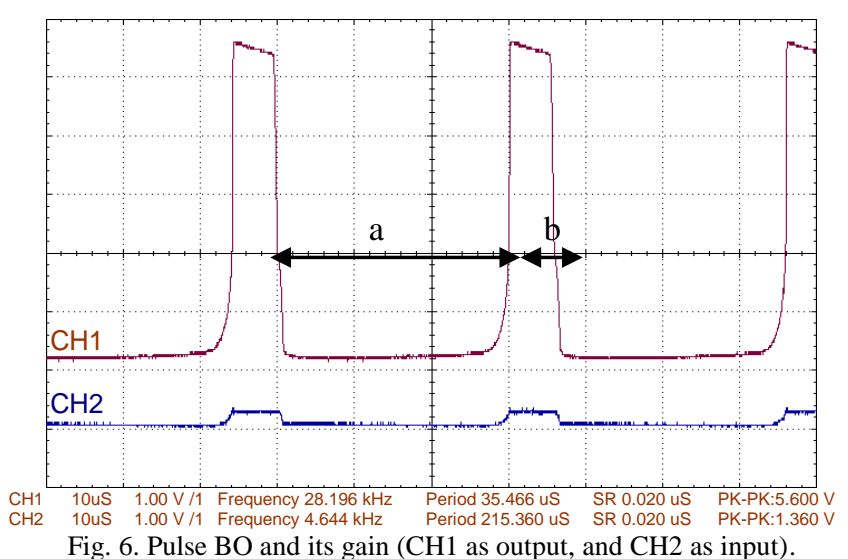

In order to optimize the power needed by LED by increase the current but the excess voltage would not being dissipated into heat thus the output voltage needs to be limited. There are two options could be taken, firstly, the number of secondary toroid turns which was connected to collector being reduced just enough to fulfill the voltage needed by LED. Second, the system may use higher input voltage for the power supply.

The voltage, number of turns and current are correlated to each other and obey to equation (3) [17].

$$
\frac{V_{s}}{V_{p}}=\frac{N_{s}}{N_{p}}=\frac{I_{p}}{I_{s}}
$$

The equation 3 warranties that the collector-emitter voltage $V_{s}$ could be decreased by secondary turns Ns limitation on the inductor as the result the output current $I_{S}$ would increase automatically. Besides that the base-emitter voltage $V_{E}$ should be adjusted to saturation voltage about 0.7 volts for silicon type [5]. 
Furthermore, when input voltage $V_{\text {in }}$ of blocking oscillator system uses new battery or higher voltage but no more then voltage needed by the load then the input current $I_{p}$ will raise as well, consequently the output current $I_{s}$ would increase.

The gain calculation from systems was done by comparing the output voltage with input voltage which was fed into system. The calculation was determined by equation (4).

$$
\text { gain }=\frac{\text { output voltage }}{\text { input voltage }}
$$

The gain is taken from Fig. 5 which is measured without any load.

$$
\max \text { gain }=\frac{4.2}{0.6}=7 \text { times }
$$

whereas,

$$
\text { min gain }=\frac{7.9}{5}=1.58 \text { times }
$$

The calculation shows that the biggest gain could be produced when the input voltage is $0.6 \mathrm{~V}$. Whereas the value follows the input voltage needed by transistor to fulfilled the requirement of saturation voltage. It means that to have more efficient, the system may use germanium transistor which need $0.3 \mathrm{~V}$ as the saturation voltage.

\section{CONCLUSION}

It has been proved that a Simple Blocking Oscillator produces high voltage pulses gain approximately to 7 times bigger than its input voltage. The gain is caused by the inductor's magnetic field as a response of high speed pulse of current feeds from the power source that is regulated by the resistor and transistor, respectively. It has high potency to use the energy of batteries until it is really dried. The pulses produced by the system make it safe for powering LED although it is passed by voltage higher than it should be.

One thing should be considered is that the current output flows to LED was too small. For a LED at least it needs current $20 \mathrm{~mA}$ whereas blocking oscillator only produces $0.12 \mathrm{~mA}$. Therefore, a new blocking oscillator system design is needed in order to increase the current. For this purpose, using high output current transistor may be used.

Additionally, to increase the efficiency of the simple blocking oscillator system germanium transistor might be used. Moreover number of turns on inductor will affect the efficiency as well.

\section{REFERENCES}

[1] A. Wang, B. H. Choun, and A. P. Chandracasan, Sub-Threshold Design for Ultra Low-Power Systems, New York: Springer, 2006.

[2] A. Bansal, M. K. Raja, and J. Minkyu, "A $52 \mathrm{nW}, 18 \mathrm{ppm} /{ }^{\circ} \mathrm{C}$, voltage reference circuit using BJTs and subthreshold mosfet," International Journal of Information and Electronics Engineering, vol. 3, no. 1, pp. 24-27, January 2013

[3] D. Chattopadhyay, P. C. Rakshit, B. Saha, and N. N. Purkait, Dasar Elektronik, UI-Press 1989, p. 256.

[4] M. Irving and P. E. Gottlieb, Practical Oscillator Handbook, Division of Reed Educational and Professional Publishing, 1997, pp. 129-131.

[5] Fairchild. (2002). Epitaxial silicon transistor. Fairchild Semiconductor Corporation. [Online]. pp. 1-6. Available: http://www.fairchildsemi.com
[6] Everlight. (2006) Technical Data Sheet $5 \mathrm{~mm}$ Round White LED (T-13/4). [Online]. pp. 1-9. Available: http://www.everlight.com

[7] A. A. Bergh, "Blue laser diode (LD) and light emitting diode (LED) applications," Phys. Status Solidi. A, vol. 201, pp. 2740-2754, 2004.

[8] S. Pimputkar et al., "Prospects for LED lighting," Nat. Photonics, vol. 3, pp. 180-182, 2009 .

[9] P. K. Buah-Bassuah et al., "A portable fibre-probe ultraviolet light emitting diode (LED)-induced fluorescence detection system," Meas. Sci. Technol, vol. 19, no. 2, pp. 72-83, 2008.

[10] P. K. Dasgupta, I.-Y. Eom, K. J. Morris, and J. Li, "Light emitting diode-based detectors absorbance, fluorescence and spectroelectro chemical measurements in a planar flow-through cell," Anal. Chim. Acta, vol. 500, no. 1-2, pp. 337-364, 2003.

[11] P. C. Hauser, C. L. C. Liang, and B. Müller, "A solid-state instrument for fluorescence chemical sensors using a blue light-emitting diode of high intensity," Meas. Sci. Technol, vol. 6, pp. 1081-1085, 1995.

[12] P. Herman, B. P. Maliwal, H. J. Lin, and J. R. Lakowicz, "Frequency-domain fluorescence microscopy with the LED as a light source," J. Microscopy-Oxford, vol. 203, pp. 176-181, 2001.

[13] H. Albert et al., "Performance of three LED-based fluorescence microscopy systems for detection of tuberculosis in Uganda," PLoS One, vol. 5, no. 12, 2010.

[14] K. Davitt et al., "290 and $340 \mathrm{~nm}$ UV LED arrays for fluorescence detection from single airborne particles," Opt. Express, vol. 13, no. 23 , pp. 9548-9555, 2005.

[15] J. Milman and H. Taub, Pulse, Digital, and Switching Waveforms: Devices and Circuits for Their Generation and Processing, Mcgraw-Hill Book Company, 1965, pp. 597-601.

[16] L. Smith, Cutting off the Plate Current by a High Negative Bias on the Radiotron Designers Handbook, NY: McGraw-Hill, 2000, p. 1398.

[17] A. A. Adegbemile, "Design of a blocking oscillator for low voltage fluorescent lighting," Int. J. of Elec. \& Power Eng., vol. 2, pp. 71-76.

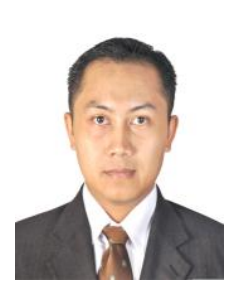

Dewanto Harjunowibowo was born in 1979 at Yogyakarta. Dewanto graduated from Gadjah Mada University in 2004 and completed his master degree from the same university in 2010. Dewanto is doctoral candidate at the Department of Architecture and Built Environment Research Division Sustainable Energy Technology, University of Nottingham, UK His research interests are image processing, artificial intelligence, energy conversion, and solar cooling.

Dewanto is working as a lecturer and a researcher in University of Sebelas Maret. He is a member of professional societies such as Indonesian Physics Society, World Society of Sustainable Energy Technologies (WSSET), International Association of Computer Science and Information Technology (IACSIT), and member of South Asia Institute of Science and Engineering (SAISE).

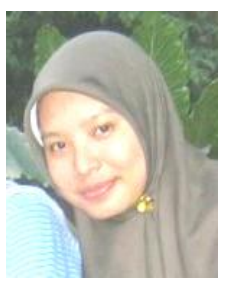

Wiwit Widiawati was born in 1992 at Ngawi. Wiwit graduated from the Physics Education Department of Sebelas Maret University in 2015. Her research interests are energy conversion, and physics education.

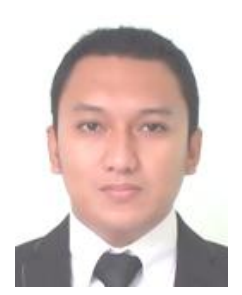

Furqan Idris was born at South Sulawesi in 1984, graduated from Electrical Engineering of Hasanuddin University. Currently, he is doing his M.Sc. degree in electrical engineering for sustainable and renewable energy at University of Nottingham, UK.

$\mathrm{He}$ is working as an energy management engineer at National Electricity Company in Indonesia - PT PLN (Persero) since 2007, also working as a freelance lecturer in PLN Corporate University.

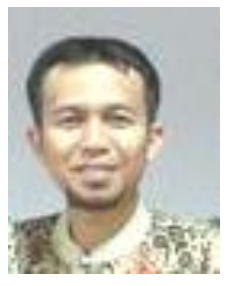

Anif Jamaluddin was born in 1980 at Pati. He graduated from Diponegoro University in 2002 and completed his master degree from Indonesia University, 2008. His research interests are harvesting energy, electronics materials, and instrumentation.

Anif is working as a lecturer and a researcher in University of Sebelas Maret. $\mathrm{He}$ is a member of professional societies such as Indonesian Physics Society. 